\title{
German Roentgen Society Statement on MR Imaging of Patients with Cardiac Pacemakers
}

\section{Positionspapier der Deutschen Röntgengesellschaft (DRG) zu MR-Untersuchungen bei Patienten mit Herzschrittmachern}

Authors

Affiliations
T. Sommer ${ }^{1}$, R. Luechinger ${ }^{2}$, J. Barkhausen ${ }^{3}$, M. Gutberlet ${ }^{4}$, H. H. Quick ${ }^{5}$, K. Fischbach ${ }^{6}$

Members of the Working Group on Cardiovascular Imaging, German Roentgen Society (DRG)

Affiliation addresses are listed at the end of the article.

\author{
Key words \\ - safety \\ - magnetic resonance imaging \\ - cardiac \\ - MRI, pacemaker \\ - MRI, implants \\ - MRI, specific absorption rate
}

received 23.3.2015

accepted $\quad 8.6 .2015$

Bibliography

DOI http://dx.doi.org/

10-1055-s-0035-1553337

Published online: 2015

Fortschr Röntgenstr 2015; 187:

777-787 @ Georg Thieme

Verlag KG Stuttgart . New York .

ISSN 1438-9029

\section{Correspondence}

\section{PD Dr. Torsten Sommer}

Klinik für Diagnostische und Interventionelle Radiologie DRK Krankenhaus Neuwied Tel.: ++ 49/2631/981751

Fax: ++49/2631/981790 torsten.sommer@drk-khneuwied.de

\section{Abstract \\ $\nabla$}

The aim of this paper is to inform physicians, especially radiologists and cardiologists, about the technical and electrophysiological background of MR imaging of patients with implanted cardiac pacemakers (PM) and to provide dedicated clinical practice guidelines how to perform MR exams in this patient group. The presence of a conventional PM system is not any more considered an absolute contraindication for MR imaging. The prerequisites for MR imaging on pacemaker patients include the assessment of the individual risk/benefit ratio as well as to obtain full informed consent about the off label character of the procedure and all associated risks. Furthermore the use of special PM-related (e.g. re-programming of the PM) and MRI-related (e. g. limitation of whole body SAR to $2 \mathrm{~W} / \mathrm{kg}$ ) precautions is required and needs to be combined with adequate monitoring during MR imaging using continuous pulsoximetry. MR conditional PM devices are tested and approved for the use in the MR environment under certain conditions, including the field strength and gradient slew rate of the MR system, the maximum whole body SAR value and the presence of MR imaging exclusion zones. Safe MR imaging of patients with MR conditional PM requires the knowledge of the specific conditions of each PM system. If MR imaging within these specific conditions cannot be guaranteed in a given patient, the procedure guidelines for conventional PM should be used. The complexity of MR imaging of PM patients requires close cooperation of radiologists and cardiologists.
Key Points:

- Conventional pacemaker systems are no longer an absolute but rather a relative contraindication for performing an MR examination.

- The procedural management of conventional pacemaker includes the assessment of the individual risk/benefit ratio, comprehensive patient informed consent about specific related risks and "off label" use, extensive PM- and MRI-related safety precautions as well as adequate monitoring techniques during the MR exam.

- Decisive for patient safety are precise understanding of, and compliance with, the terms of use for the specific MR-conditional pacemaker system.

- If the electrophysiological and MRI-specific conditions for use of MR-conditional pacemakers are not met or compliance with these conditions for use cannot be guaranteed, the device must be treated like a conventional pacemaker.

Citation Format:

- Sommer T, Luechinger R, Barkhausen J et al. German Roentgen Society Statement on MR Imaging of Patients with Cardiac Pacemakers. Fortschr Röntgenstr 2015; 187: 777-787

\section{Zusammenfassung \\ $\nabla$}

Ziel dieses Positionspapiers der AG Herz- und Gefäßdiagnostik der Deutschen Röntgengesellschaft ist es, Ärzte aller Fachbereiche - insbesondere die primär involvierten Fachgruppen der Radiologen und Kardiologen - über die Möglichkeiten, Grenzen und Risiken von MRT-Untersuchungen bei Patienten mit konventionellen und bedingt MRT-sicheren Herzschrittmachersystemen (SM) zu informieren und dezidierte Handlungsempfehlun- 
gen zur Durchführung von MRT-Untersuchungen bei diesen Patienten auszusprechen. Konventionelle Herzschrittmachersysteme sind nicht mehr als eine absolute, sondern als eine relative Kontraindikation für die Durchführung einer MRT-Untersuchung anzusehen. Entscheidend bei Indikationsstellung und Untersuchungsdurchführung sind die Abschätzung des individuellen Nutzen/Risiko-Verhältnisses sowie eine umfassende Aufklärung über die zulassungsüberschreitende Anwendung („off label use“) als individuelle Einzelfallentscheidung und über die mit der MRTUntersuchung assoziierten spezifischen Risiken. Des Weiteren sind umfangreiche SM-bezogene (Umprogrammierung des SM) und MRT-bezogene Sicherheitsmaßnahmen (u.a. Limitation der Ganzkörper-SAR-Werte auf $2 \mathrm{~W} / \mathrm{kg}$ ) zur weitestgehenden Reduzierung dieser Risiken sowie adäquate Monitortechniken (insbesondere kontinuierliche pulsoxymetrische Überwachung) während der MRT-Untersuchung erforderlich. Bedingt MRT-sichere („MR conditional“) Herzschrittmachersysteme sind für eine MRUntersuchung unter dezidierten Rahmenbedingungen getestet und zugelassen („in label use“). Die Hersteller gewährleisten die Sicherheit bei korrekter Anwendung im Rahmen der spezifischen Nutzungsbedingungen, die u.a. Vorgaben bezüglich der Feldstärke des MRT-Systems, der maximalen Anstiegssteilheit („slew rate“) des Gradientensystems, dem maximal erlaubten Ganzkörper-SAR u. dem MR-tomografisch untersuchbaren Bereich (Ganzvs. Teilkörperzulassung des SM-Systems) beinhalten sowie die Überprüfung diverser elektophysiologischer Parameter (u. a. elektrisch intakte Elektroden, keine gekappten „abandoned“ Elektroden, keine anderweitigen zusätzlichen Elektroden) verlangen. Entscheidend für die Patientensicherheit sind die genaue Kenntnis und die Einhaltung der für das jeweilige Schrittmachersystem spezifischen Nutzungsbedingungen. Sollte dies nicht gewährleistet werden können, wird ein Vorgehen wie bei Patienten mit konventionellen Herzschrittmachern empfohlen. Grundsätzlich erfordert das vorgestellte prozedurale Management von MRTUntersuchungen bei Patienten mit konventionellen und bedingt MRT-sicheren Herzschrittmachern eine enge Kooperation zwischen Radiologie und Kardiologie.

\section{Introduction}

Due to excellent soft tissue contrast and absence of radiation exposure, magnetic resonance imaging (MRI) is currently recommended by European and American guidelines as the imaging method of choice in many clinical scenarios [1 - 4]. Parallel to this, the number of patients with implanted cardiac pacemakers (PM) continues to increase; in Germany alone, the new implantation rate is about 75000 annually, with approximately 600000 patients currently living with the device [5]. It is estimated that due to existing comorbidities, approximately $70 \%$ of these typically older patients will exhibit a clinical indication for an MR examination at least once in the course of their lives [6].

However, there are numerous possible interactions between the static and pulsed electromagnetic fields of a magnetic resonance imaging system and a pacemaker system [6 - 19]. Essentially these interactions pose three main risks - each potentially life-threatening - for a pacemaker patient during an MR examination:

1. False perception of pulsed MRI gradient fields as intrinsic cardiac activity with inhibition of the pacemaker stimu- lation function and consecutive asystole in pacemakerdependent patients,

2 . voltage induction into the pacemaker leads through coupling of the magnetic pulsating fields in a metallic conductor with asynchronous myocardial stimulation and the potential risk of induction of ventricular tachycardia/ ventricular fibrillation, as well as

3. strong local concentration of the energy of the high frequency field due to the antenna effect of the pacemaker leads with potential thermal damage in the myocardium/endocardium at the lead tips and consecutive ineffective PM stimulation due to increase of the pacing capture threshold.

With this in mind, two developments should be mentioned which have high clinical relevance for the management of patients with pacemakers scheduled for MR imaging:

1. Based on scientific studies and clinical experience over the past 15 years [7-14, $20-28$ ], the presence of a conventional pacemaker system - according to the overwhelming majority of experts and relevant national and international professional associations $[9,29]$ - no longer represents an absolute, but rather a relative contraindication for an MR exam. MRI can be performed taking into consideration the individual risk/benefit profile as a single-case decision and as "off-label" use applying dedicated safety measures.

2. In 2008 a new technology, so-called "MR conditional" pacemaker systems were introduced, initially by Medtronic, and are now provided by all pacemaker manufacturers. These PM systems - defined as a functional unit composed of pacemaker pulse generator and leads - are tested and approved for MRI under certain conditions ("inlabel" use) [24]. The problem with these conditions is that they can vary significantly depending on the manufacturer and specific pacemaker model. Decisive for patient safety during an MR examination is precise understanding of, and compliance with, these conditions and the terms of use for the specific pacemaker system.

Recent experience in Germany has shown that there are currently a few specialized centers that perform MRI on patients with MR conditional pacemaker systems. Nevertheless, an MR exam is still withheld from many patients with pacemakers, even when the pacemaker is conditionally MRI-safe. One reason for this is a significant lack of information and legal uncertainty on the part of both radiology and cardiology with respect to dealing concretely in the clinical setting with these new developments and the technically complex and interdisciplinary issue.

The aim of these clinical practice guidelines of the German Radiology Society (DRG), Working Group on Cardiovascular Imaging is to present, from the radiological viewpoint, necessary background knowledge and to express specific recommendations for performing MR imaging on patients with conventional and MR conditional cardiac pacemaker systems.

In the medium term, development of a sufficient number of centers with relevant expertise should be encouraged in order to guarantee enough clinical MRI facilities for the large patient population with pacemakers in Germany.

Further, these clinical practice guidelines should substantiate and supplement from the radiological perspective the abbreviated description of this complex topic in the current 
guidelines of the European Society of Cardiology [29], and provide corrections of some points.

\section{MRI of patients with conventional pacemakers}

The recommended procedural management of patients with conventional pacemakers is shown in Algorithm 1 ( $\bullet$ Fig. 1). The individual steps are explained below.

\section{Critical review of indications for MR imaging}

The clinical urgency and therapeutic consequences of a requested MR examination should be documented by the referring clinical physician; the lack of adequate imaging alternatives should be indicated by the attending radiologist. An interdisciplinary decision regarding the performance or withholding of the examination should be made on a caseby-case basis by the referring physician, cardiologist and radiologist.

Critical for this decision is the estimation of the individual risk/benefit ratio taking into account the electrophysiological risk profile ( $\triangle$ Table 1 ), the specific risk of the respective region to be examined ( $\bullet$ Table 2 ), as well as local circumstances (expertise and collaboration among attending radiological and cardiological personnel, guarantee of qualified patient monitoring during the MR examination, as well as adequate management of any possible emergency situation).

Due to its primary significance in determining the indication for examination and review in the case of a patient with a conventional pacemaker, this risk/benefit analysis is illustrated using a few examples.

The expected benefit of an MRI scan of the brain when planning surgery of an intracerebral tumor in a patient with a pacemaker should usually be rated as high. The relatively low risk profile of an MR examination of the brain ( $\triangle \mathrm{Ta}$ ble 2) - particularly in the absence of additional risk-elevating electrophysiological parameters ( $\bullet$ Table 1 ) - would essentially support performing an MRI scan, based on the risk/benefit ratio.

On the other hand, an MR examination of the thoracic spine of a patient with a conventional pacemaker should be undertaken with extreme caution due to the significantly increased risk of HF-induced heating effects of the leads in this anatomical region ( $\bullet$ Table 2 ). However, in a case of urgent clinical indication such as incipient paraparesis related to decompensated spondylodiscitis, the anticipated clinical benefit may be so great that this increased risk can be considered acceptable, particularly if the patient is not pacemaker-dependent, so that the primary risk of ineffective pacemaker stimulation due to heating-induced increased pacing capture thresholds is of lower clinical importance.

Of the electrophysiological risk parameters illustrated in - Table 1, the first three items - 1. pacemaker dependency, 2. vulnerable myocardium/increased disposition for highgrade arrhythmias, as well as 3 . abandoned pacemaker leads - should be emphasized as main risks during an MR examination of a patient with a conventional pacemaker. However, none of these three points necessarily imply withholding an MR examination if - taking into account the urgent clinical need for MR imaging - the specific risk/benefit ratio is considered positive for the patient on the whole.
Table 1 High risk electrophysiological parameters for MRI of PM patients.

\begin{tabular}{|c|c|}
\hline electrophysiological parameters & potential hazards \\
\hline $\begin{array}{l}\text { pacemaker-dependence } \\
\text { of patient }\end{array}$ & $\begin{array}{l}\text { ineffective stimulation due to } \\
\text { RF-induced tissue heating at the } \\
\text { tips of the leads with increase of } \\
\text { the pacing capture thresholds } \\
\text { inhibition of stimulation due to } \\
\text { gradient fields (false sensing) }\end{array}$ \\
\hline $\begin{array}{l}\text { vulnerable myocardium (acute/ } \\
\text { subacute myocardial infarction, } \\
\text { acute myocarditis), arrhythmo- } \\
\text { genic substrate/structural cardi- } \\
\text { ac disease }\end{array}$ & $\begin{array}{l}\text { increased risk for induction of } \\
\text { ventricular fibrillation/ventricular } \\
\text { tachycardia via voltage induction } \\
\text { in the leads due to gradient fields } \\
\text { or rectified RF fields }\end{array}$ \\
\hline abandoned pacemaker leads & $\begin{array}{l}\text { elevated risk of RF-induced tissue } \\
\text { heating on the tips of abandoned } \\
\text { leads compared to leads connec- } \\
\text { ted to the pacemaker system }\end{array}$ \\
\hline $\begin{array}{l}\text { additional leads (e. g. coronary } \\
\text { sinus/epicardial leads) } \\
\text { lead extensions, adapters }\end{array}$ & $\begin{array}{l}\text { elevated risk of RF-induced heat- } \\
\text { ing effects at the lead tips due to } \\
\text { addition of the individual antenna } \\
\text { effects and/or elongation of the } \\
\text { antenna route of the leads }\end{array}$ \\
\hline lead defect & $\begin{array}{l}\text { elevated risk of RF-induced } \\
\text { heating effects at the lead tips }\end{array}$ \\
\hline $\begin{array}{l}\text { metallic cardiac or extracardiac } \\
\text { implants (length }>5 \mathrm{~cm} \text { ) directly } \\
\text { adjacent }(<4 \mathrm{~cm}) \text { to the leads }\end{array}$ & $\begin{array}{l}\text { elevated risk of RF-induced heat- } \\
\text { ing effects at the lead tips due to } \\
\text { addition of the individual antenna } \\
\text { effects }\end{array}$ \\
\hline $\begin{array}{l}\text { primarily increased pacing } \\
\text { capture thresholds }\end{array}$ & $\begin{array}{l}\text { insufficient stimulation due to RF- } \\
\text { induced tissue heating at the tips } \\
\text { of the leads with further increase } \\
\text { of the pacing capture thresholds }\end{array}$ \\
\hline $\begin{array}{l}\text { low battery voltage (ERI, EOL } \\
\text { criteria) }\end{array}$ & $\begin{array}{l}\text { elevated risk of switching into } \\
\text { emergency mode (electrical } \\
\text { reset), which is usually VVI }\end{array}$ \\
\hline implantation time $<6$ weeks & $\begin{array}{l}\text { unstable pacing capture thresh- } \\
\text { olds in the healing phase after lead } \\
\text { implantation }\end{array}$ \\
\hline
\end{tabular}

Table 2 Risk assessment of the MR examination region of patients with pacemakers.

\begin{tabular}{|c|c|}
\hline $\begin{array}{l}\text { MR examination region: } \\
\text { higher risk }\end{array}$ & potential hazards \\
\hline $\begin{array}{l}\text { thoracic spine, heart, chest, } \\
\text { breast, shoulder }\end{array}$ & $\begin{array}{l}\text { leads located completely in RF } \\
\text { transmitter coil with increased } \\
\text { coupling of RF energy and poten- } \\
\text { tially increased heating effects at } \\
\text { the lead tips }\end{array}$ \\
\hline $\begin{array}{l}\text { MR examination region: } \\
\text { lower risk }\end{array}$ & potential hazards \\
\hline brain, pelvis, hip joint, knee, foot & $\begin{array}{l}\text { leads outside/largely outside RF } \\
\text { transmitter coil with limited RF } \\
\text { energy coupling and only minimal } \\
\text { heating effects at the lead tips }\end{array}$ \\
\hline
\end{tabular}

\section{Patient information / informed consent}

During an appropriate time frame prior to the MR examination, the patient should be specifically informed regarding the following circumstances and risks.

1. MRI on a patient with a conventional pacemaker is a nonapproved ("off-label") procedure based on a case-by-case decision on the part of the attending physicians. The relevant authorities have not issued certification for the MR examination, and neither the pacemaker manufacturer 
nor the manufacturer of the MRI equipment will be liable for any damage or complications.

2. An MR examination of a patient with a conventional pacemaker system poses the following risks and complications:

v damage to the pacemaker generator with the necessity of replacement

- malfunction of the pacemaker leads, e.g. due to heating-related increase of pacing capture thresholds, necessitating revision/new implantation of leads

v heating of the pacemaker leads resulting in thermal damage to the cardiac muscle (acute or chronic) and ineffective pacemaker stimulation as a potentially lifethreatening complication in the case of absolute PM dependency of the patient

> induction of potentially life-threatening tachycardia arrhythmia

> inhibition of pacemaker therapy of spontaneous bradyarrhythmic episodes occurring during the MRI scan with potentially life-threatening consequences in patients with absolute PM dependency

Occurrence of the risks described above can be minimized by employing specific safety precautions; however these risks cannot be absolutely eliminated and are not quantifiable in individual cases.

\section{Monitoring during MRI}

A decisive element of safety in the procedural management of patients with conventional pacemakers is adequate monitoring of vital functions in order to detect and treat potentially life-threatening complications early - in particular the occurrence of high-grade ventricular arrhythmias, ventricular fibrillation or spontaneous episodes of bradycardia. Continuous pulse oximetry monitoring is mandatory, displaying the peripheral pulse wave and oxygen saturation using a pulse oximeter certified for patient monitoring in the MR environment. It should be noted that the pulse wave display integrated into most MRI systems is not sufficient on its own. The advantage of pulse oximetry monitoring is that it is not affected by either the static magnetic field or the pulsed radio frequency (RF) and gradient fields, thus allowing accurate assessment of the heart rate as well as oxygen saturation of the patient in the MR environment. Accurate rhythm analysis (differentiation between atrial and ventricular tachycardia) is not possible, but also not mandatory during an MR examination. In the event of a hemodynamically significant bradycardiac or tachycardiac arrhythmia indicated by a decrease of oxygen saturation, the examination must be immediately discontinued and the patient brought out of the MRI room into an area in which standard emergency equipment can be employed. In this context it should be noted that defibrillation in the static magnetic field or within the 5-Gauss line is absolutely contraindicated due to magnetic attraction forces acting on the defibrillator. Furthermore, in a strong static magnetic field - such as in the direct vicinity of a 1.5 T MRI system charging the capacitor of a defibrillator and thus generating a therapeutic shock, is technically not possible with currently available equipment.

ECG monitoring as the sole control modality during MRI of patients with conventional pacemakers, is definitely insufficient due to artifacts induced by pulsed RF and gradient fields. However, it is recommended as a monitoring modality supplementary to pulse oximetry, particularly when the examination has a high risk profile. In this instance as well, an MRI-compatible ECG unit certified for patient monitoring in the MR environment should be used.

The monitoring phase starts immediately upon entry into the MRI room. It is recommended to attach the pulse oximeter as well as to establish i.v. access outside the MRI room. During the MR examination, continuous verbal and visual contact with the patient should be guaranteed, and the patient should be instructed to immediately report any symptoms such as palpitations, dizziness, heat sensation or movement in the pacemaker pocket.

In order to respond immediately to high-grade ventricular arrhythmias as well as episodes of spontaneous bradycardia, on-site availability of a defibrillator as well as a programmer compatible with the respective pacemaker system is absolutely mandatory.

For safety reasons, the presence of a cardiologist during MRI should be requested for patients with conventional pacemaker systems and higher risk profile ( $\bullet$ Table 1 ) - particularly for patients with absolute PM dependency, for patients with abandoned pacemaker leads, as well as for patients with vulnerable myocardium.

For practical reasons, it would be reasonable for conventional pacemaker patients with a low risk profile ( $\bullet$ Table 1, 2 ) to have a cardiologist available on an emergency standby basis rather than being continuously present during MRI. In this case, adequate patient monitoring during the MR examination should be guaranteed by the presence of a physician who is capable to treat the patient properly until the arrival of a cardiologist.

\section{MRI-related safety precautions}

By far, the most numerous clinical experiences are with closed/cylindrical MRI units with a field strength of 1.5T; thus these MRI systems are preferable for scheduled MR examinations of patients with conventional pacemakers $[6,8$, $10,11,22-25]$. There are studies demonstrating the safety of MRI of the brain using a field strength of $3 \mathrm{~T}$ [20]. Due to the lack of sufficient data, open MRI systems should not be employed.

The built-in body RF coil, a large volume coil integrated permanently in the MR scanner, should be used as the RF transmitter coil. Local transmit/receive coils are absolutely contraindicated in the thoracic region. The use of local receiver coils is non-critical and possible in all regions of the body - including the chest - if the integrated body RF coil is used as the transmitter coil.

RF-induced heating of the PM leads cannot be predicted in individual cases, as it is dependent on numerous influencing parameters, including position and configuration of the PM leads in the patient as well as position relative to the RF transmitter coil, relation of the wave length of the RF excitation pulse to the effective lead length, SAR value (specific absorption rate) of the MRI sequence used. The SAR value (unit $\mathrm{W} / \mathrm{kg}$ ) is a measure of the absorption of electromagnetic field energy in biological tissue. To limit consecutive tissue heating during an MRI scan, the radio frequency power irradiated into the body is monitored on the equipment and the corresponding SAR value is displayed. In keeping with legally-mandated IEC threshold val- 
ues, [30] the SAR value during an MR examination must not exceed $4 \mathrm{~W} / \mathrm{kg}$ in the whole body or $3.2 \mathrm{~W} / \mathrm{kg}$ in the head independent of the presence or absence of a pacemaker or an otherwise active or inactive implant.

If all other influential parameters remain constant, there is a linear relationship between the SAR value of the related MRI sequence and tissue heating at the tip of the pacemaker lead. This RF-induced tissue heating can thus be simply and effectively reduced by limiting the SAR value. It is therefore strongly recommended that during MR examinations of patients with conventional pacemakers, the SAR value of all MRI sequences should be limited to $<2 \mathrm{~W} / \mathrm{kg}$ in the whole body (upper threshold of normal operating mode) and $<3.2 \mathrm{~W} / \mathrm{kg}$ in the head.

Compliance with these SAR thresholds during a standard sequencing protocol without relevant decrease of image quality is usually possible in routine clinical situations. MRI systems made by all manufacturers include standard simple software options that, by selecting the normal operating mode, ensure that the MRI parameters of the selected sequence is automatically adapted such that the SAR threshold of $2 \mathrm{~W} / \mathrm{kg}$ in the whole body and $3.2 \mathrm{~W} / \mathrm{kg}$ in the head is not exceeded.

Basically it is also possible to reduce the SAR value manually by modifying individual sequence parameters in order to remain in the normal operating mode:

- reduction of number of slices

- reduction of turbo factor

- replacement of spin echo or turbo spin echo sequences with gradient echo sequences

- reduction of excitation angle during gradient echo sequences

- replacement of steady-state free precession sequences with gradient echo sequences, particularly in cardiac imaging.

A limitation of the active examination time (cumulative examination time with active gradient and RF fields) to a maximum of 30 minutes is recommended in order to minimize the risk of thermal endo-/myocardial damage due to RF-induced lead heating which is dependent not only on the level but also on the duration of the heating.

\section{Pacemaker-related safety precautions}

The pacemaker system should be reprogrammed immediately prior to the MRI scan, and then reprogrammed again to its original mode immediately after the MR examination. The attending cardiologist determines and takes responsibility for the pacemaker mode during MRI. Specific current reprogramming and monitoring guidelines, taking into account safety as well as practical aspects are currently being developed in collaboration with the German Cardiac Society. Until then, the following procedure is recommended; the cardiologist should view it as a framework which can be modified on an individual basis, depending on the specific electrophysiological situation of the patient.

a) In the case of a pacemaker-dependent patient: reprogram the pacemaker into an asynchronous mode (D00, V00) with deactivation of the sensing function. This will prevent inhibition of the pacemaker by pulsed magnetic fields while ensuring continuous cardiac stimulation of the patient.

b) In the case of a non-pacemaker-dependent patient (representing approx. $80 \%$ of pacemaker patients): repro- gram the pacemaker into a SENSE-only mode (e.g. ODO) with deactivation of the stimulation function or, if the PM system allows, complete deactivation of the pacemaker (000) in order to prevent improperly triggered atrial and/or ventricular stimulation or asynchronous stimulation after reed switch actuation or during interference mode.

c) Increase the stimulation pulse (e.g. to $5.0 \mathrm{~V} / 1.0 \mathrm{~ms}$ ), in order to compensate for a possible increase of the pacing capture threshold caused by heating of the pacemaker leads.

d) Reprogram the sensing and stimulation polarity of the pacemaker leads to bipolar (if technically possible).

e) Deactivate all supplemental stimulation functions (i.e. frequency-adapted stimulation, anti-tachycardia stimulation).

A complete PM interrogation should be performed both immediately before as well as after the MR examination as part of the reprogramming procedure, as well as 3 months afterward. The 3 months follow-up is done to detect any delayed damage/malfunctions induced during the MRI (e.g. chronic increased pacing capture thresholds resulting from scar tissue formation).

\section{MRI of patients with MR conditional pacemaker systems \\ $\nabla$}

MR conditional pacemakers have been tested for an MR examination under specific conditions, and approved for use by the European Medical Device Directive with CE certification ("in-label" use). The manufacturer guarantees its safety when properly used following specific conditions for use. The Medtronic company has published prospective randomized multi-center studies demonstrating the safety of the Enrhythm and Advisa models [31 - 33].

Technical modifications of MR conditional pacemaker systems include replacement of the reed switch with a Hall sensor (unlike a standard reed switch, its behavior is predictable in a strong static magnetic field), improved protection of the internal circuits (thereby avoiding electromagnetic interference and voltage drop-induced electrical resets); modification of input capacities and protective diodes in the pacemaker system (to reduce voltage induction into the leads), as well as a software-based MRI protective mode (see below).

Some manufacturers (Medtronic, St. Jude, Boston Scientific) have developed new leads in which RF-induced heating is significantly reduced. In addition, all manufacturers have tested their conventional leads and have identified some lead models, which under certain conditions could be approved as MR conditional (back labeling). This implies that a lead primarily labeled "conventional" and not "MR-safe" on the pacemaker ID card during implantation could be retrospectively tested and approved as "MR conditional". This emphasizes that data regarding MR safety of the leads in the pacemaker ID card may not be reliable, and should be currently reviewed with the manufacturer (manual, hotline, web site, 0 Table 3 ).

The recommended procedural management of patients with MR conditional pacemakers is shown in Algorithm 2 (৫ Fig. 2). The individual steps are explained below. 
It should be noted that all information is only a snapshot of the current situation. Changes to the conditions for use are possible, and it is necessary to review each case individually and in a timely manner. Therefore, the telephone hotline numbers as well as the related Internet addresses of the individual manufacturers are provided in 0 Table 3.

\section{Indications and review of the conditions for use}

In the cardiac/pacemaker outpatient clinic PM interrogation, and if necessary a review of the medical record of the center performing the implantation, is performed to determine whether the pacemaker-specific conditions of use are fulfilled for MR imaging.

In cases of doubt an X-ray of the chest may be performed, especially to exclude points 7 and 8 (see below).

1. Verification of a complete and approved MR conditional pacemaker system consisting of a pacemaker generator and pacemaker leads

2. Left or right pectoral implantation site of the pacemaker system

3. Implantation time $>6$ weeks

4. Electrically intact pacemaker leads

5. Pacing capture thresholds within the normal range

6. Sufficient battery capacity based on the manufacturer's specification

7. No additional cardiac leads (particularly no abandoned pacemaker leads), no additional components such as lead adapters or extensions

8. Exclusion of other cardiac implants, depending on the manufacturer's specification (e.g. coronary stents, prosthetic heart valves), ${ }^{1}$ Table 3

9. Written documentation (check list) by the attending cardiologist indicating that the electrophysiological conditions for use of the pacemaker have been fulfilled.

Radiology performs verification of the MR-related conditions for use:

1. Design and field strength of the MRI system: The MR conditional pacemaker systems of all manufacturers are approved for an MRI scan in closed/cylindrical MRI systems with a field strength of $1.5 \mathrm{~T}$. For some of their pacemaker systems, Biotronik and Boston Scientific also have additional approval for MRI systems with a field strength of $3 \mathrm{~T}$. Currently no MR conditional pacemaker system has approval for MRI examinations with a field strength $1 \mathrm{~T}$ or lower nor is there approval for open MRI systems.

\footnotetext{
${ }^{1}$ The problem of the presence of other implants, such as cardiac implants (e.g. coronary stents, prosthetic heart valves) or extracardiac implants (e.g. spondylodesis material in the thoracic spine), arises from the fact that the superposition of RF-induced electromagnetic fields upon these implants combined with those of the pacemaker system results in additive effects which can lead to increased heating of the leads. A potential hazard arises if an implant in the critical vicinity of the pacemaker leads exhibits a related antenna effect on its own with subsequent increased heating of the leads. In the case of their MR conditional pacemaker systems, the manufacturers Medtronic and Biotronik therefore explicitly permit only the presence of "other cardiac and extracardiac implants" if such an implant is likewise approved as MR conditional on its own. Furthermore, in addition to the conditions for use of the pacemaker system, also the conditions for use of these implants have to be met during MRI. PM of Biotronik additionally require that other implants in the direct vicinity of the leads $(<4 \mathrm{~cm})$ may not have a length greater than $5 \mathrm{~cm}$. The Sorin Group permits only other implants that are MRIsafe, thus effectively excluding all metallic implants.
}

Based on manufacturers' information, there are no plans for such in the future.

2. Gradient system: Most MR conditional pacemaker systems permit MRI sequences up to a maximum gradient field slew rate of $200 \mathrm{~T} / \mathrm{m} / \mathrm{s}$ per axis. Clinical MRI gradient systems currently in use do not achieve or exceed this value. An important exception are some pacemaker systems made by Biotronik, for which the maximum slew rate of the gradient fields is limited to only $125 \mathrm{~T} / \mathrm{m} / \mathrm{s}$ per axis.

Unlike the SAR value, the slew rate of the gradient fields of specific MRI sequences cannot be quantified and controlled or is difficult to quantify and control in clinical applications. Therefore, for the examination of a patient with a pacemaker, it is recommended to identify an MRI scanner with known technical specifications and maximum output of the gradient system lying below the approved limit range of the relevant pacemaker system. It should be mentioned that some manufacturers' brochures occasionally indicate higher slew rates of the gradient fields up to $350 \mathrm{~T} / \mathrm{m} / \mathrm{s}$ which then correspond to $\mathrm{cu}-$ mulative slew rates of the $\mathrm{x}, \mathrm{y}, \mathrm{z}$ gradients. However, the safety-related reference parameter is the slew rate of the gradient fields per axis.

3. Whole-body vs. partial-body approval: The manufacturers Medtronic and Boston Scientific have whole-body approval for all their MR conditional pacemaker systems, i. e. all regions of the body can in principle be examined using MRI. Biotronik and St. Jude, in addition to pacemaker systems with whole-body approval, also have systems with only partial-body approval. All Sorin Group pacemaker systems currently have only partial-body approval. For systems with only partial-body approval MRI examinations are limited to scans outside of the chest to reduce RF-induced heating of the pacemaker leads. For pacemaker systems with partial-body approval made by Biotronik and Sorin Group, MRI scans are specifically limited to those body regions in which the isocenter of the scan field (field of view) is above the orbital cavities or below the greater trochanter. Pacemaker systems made by St. Jude with partial-body approval also include model series with MRI scans limited to examinations of body regions with an isocenter of the scan field above cervical vertebra 1 and below lumbar vertebra 4, as well as model series more stringently limited to an upper isocenter position $10 \mathrm{~cm}$ above cervical vertebra 1 with an identical lower isocenter position below lumbar vertebra 4 .

4. Exclusion of other extracardiac implants, depending on the manufacturer's specification (e.g. spondylodesis material in the thoracic spine), ${ }^{1} \bullet$ Table 3

5. Written documentation (check list) by the attending radiologist indicating that the MR-related conditions for use of the pacemaker have been met.

If the manufacturer-specific electrophysiological and MRIspecific conditions for use are not met or compliance with these conditions for use cannot be guaranteed the PM device must be treated like a conventional pacemaker.

\section{Patient information}

Unlike patients with conventional pacemaker systems, performance of MRI scans on patients with MR conditional pacemaker systems are an approved application ("in-la- 


\section{Algorithm 1: MR examinations of patients with conventional pacemakers \\ $\nabla$ \\ Critical review of indication \\ - Referring physician: written documentation of the urgency of the clinical indication and therapeutic consequences \\ - Cardiology: Estimation of the cardiological/electrophysiologi- cal risk profile $(\bullet$ Table 1$)$ \\ - Radiology: Confirmation of the absence of imaging alterna- tives and risk assessment of the specific MR examination and examination region ( $\bullet$ Table 2 ) \\ - Interdisciplinary decision among the referring physician, car- diologist and radiologist regarding performing or withholding the examination, taking into account the individual risk/bene- fit profile and local conditions (technical equipment, experi- ence of clinical staff)}

\section{$\downarrow$}

Patient information/informed consent

about

- Non-approved (off-label) use

- Potential risk of:

- Damage / malfunction of pacemaker generator or leads with the necessity of PM or lead replacement

- Occurrence of potentially life-threatening arrhythmia induced by MRI

- Insufficient PM therapy of potentially life-threatening bradyarrhytmic episodes occuring spontaneously during the MR examination

$\checkmark$ Death

\section{$\downarrow$}

PM interrogation and reprogramming immediately pre-MRI

(for details, see "Pacemaker-related safety precautions")

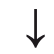

Performing the MR examination

- Limitation of active MR examination time to 30 minutes

- Limitation of SAR values of the individual MRI sequences to normal operating mode $<2 \mathrm{~W} / \mathrm{kg}$ (whole body) or $<3.2 \mathrm{~W} / \mathrm{kg}$ (head)

- Adequate patient monitoring using pulse oximeter and ECG

- Cardiologist present on-site or available on standby in the event of an emergency

- Pacemaker programming device, defibrillator and emergency equipment available on-site

- Emergency management possible according to guidelines by qualified attending personnel

\section{$\downarrow$}

PM interrogation and reprogramming immediately post-MRI

Follow-up of pacemaker function after 3 months
Algorithm 2: MR examinations of patients with MR conditional pacemaker systems

Review of indication and conditions for use

- Cardiology:

- Pacemaker interrogation with verification of a complete and intact MR conditional pacemaker system (generator and leads), as well as required model-specific electrophysiological parameters (e.g. pacing capture thresholds, lead impedance, battery capacity)

- Exclusion of abandoned pacemaker leads or other electrodes, exclusion of additional lead adapters/extensions or other metallic cardiac implants (review of patient's medical file, chest X-ray as needed)

- Radiology:

- Verification of MR-related conditions for use (e.g. field strength, gradient system, approval for whole- or partialbody scan, presence of other extracardiac metallic implants)

- Written documentation (check list) that the electrophysiological (cardiology) and MR-related conditions for use (radiology) have been fulfilled

- In a non-approved situation, proceed analogously to the algorithm "MRI with conventional pacemakers"

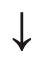

\section{Patient information/informed consent}

about

- MRI conditional PM are approved for MRI ("in label use") and risks have been widely minimized.

- However, patients must be principally informed about the same risks as those with conventional PM systems (see algorythm 1).

\section{$\downarrow$}

PM interrogation and programming into MR protection mode pre-MRI

Performing the MR examination

- Compliance with the MRI-specific conditions for use (e.g. field intensity, cylindrical MRI, gradient system, choice of receive coil, positioning, whole-vs. partial-body approval)

- Manufacturer/model-specific limitation of SAR values of the MRI sequences

- Patient monitoring using only pulse oximetry sufficient, additional ECG not obligatory

- Monitoring of examination by medical staff, standard emergency equipment on-site, presence of cardiologist not obligatory, emergency team available

\section{$\downarrow$}

PM interrogation and reprogramming into original mode post-MRI

Fig. 2 Algorithm 2 .

Fig. 1 Algorithm 1. 


\begin{tabular}{|c|c|c|c|c|c|}
\hline & medtronic & biotronik & Boston Scientific & St. Jude Medical & Sorin Group \\
\hline field strength & $1.5 \mathrm{~T}$ & $\begin{array}{l}1.5 \text { T some pacemaker systems } \\
\text { additionally } 3 \mathrm{~T}\end{array}$ & $\begin{array}{l}1.5 \text { T some pacemaker systems } \\
\text { additionally } 3 \mathrm{~T}\end{array}$ & $1.5 \mathrm{~T}$ & $1.5 \mathrm{~T}$ \\
\hline maximum gradient slew rate & $<200 \mathrm{~T} / \mathrm{m} / \mathrm{s}$ & $\begin{array}{l}<200 \mathrm{~T} / \mathrm{m} / \mathrm{s} \text { Individual models } \\
\text { only }<125 \mathrm{~T} / \mathrm{m} / \mathrm{s}\end{array}$ & $<200 \mathrm{~T} / \mathrm{m} / \mathrm{s}$ & $<200 \mathrm{~T} / \mathrm{m} / \mathrm{s}$ & $<200 \mathrm{~T} / \mathrm{m} / \mathrm{s}$ \\
\hline $\begin{array}{l}\text { maximum whole-body SAR } \\
\text { (specific absorption rate) }\end{array}$ & $\begin{array}{l}\text { for all pacemaker systems }<2 \mathrm{~W} / \\
\mathrm{kg} \text { (head } S A R<3.2 \mathrm{~W} / \mathrm{kg} \text { ) }\end{array}$ & $\begin{array}{l}<2 \mathrm{~W} / \mathrm{kg} \text { (head SAR } 3.2 \mathrm{~W} / \mathrm{kg} \text { ) } \\
\text { some pacemaker systems }<4 \mathrm{~W} / \\
\mathrm{kg}(\text { head SAR }<3.2 \mathrm{~W} / \mathrm{kg} \text { ) }\end{array}$ & $\begin{array}{l}<2 \mathrm{~W} / \mathrm{kg} \text { (head SAR }<3.2 \mathrm{~W} / \mathrm{kg}) \\
\text { some pacemaker systems }<4 \mathrm{~W} / \\
\mathrm{kg}(\text { head SAR }<3.2 \mathrm{~W} / \mathrm{kg})\end{array}$ & $\begin{array}{l}\text { both }<4 \mathrm{~W} / \mathrm{kg} \text { (head SAR }<3.2 \mathrm{~W} / \\
\mathrm{kg} \text { ) as well as some pacemaker } \\
\text { systems }<2 \mathrm{~W} / \mathrm{kg} \text { (head SAR } \\
<3.2 \mathrm{~W} / \mathrm{kg} \text { ) }\end{array}$ & $\begin{array}{l}\text { for all pacemaker systems }<2 \mathrm{~W} / \\
\mathrm{kg}(\text { head } \mathrm{SAR}<3.2 \mathrm{~W} / \mathrm{kg})\end{array}$ \\
\hline whole-/partial-body approval & $\begin{array}{l}\text { whole-body approval for all } \\
\text { pacemaker systems }\end{array}$ & $\begin{array}{l}\text { Pacemaker system-dependent } \\
\text { whole-body approval or partial- } \\
\text { body approval (isocenter of FOV } \\
\text { above the orbit or below the ma- } \\
\text { jor trochanter) }\end{array}$ & $\begin{array}{l}\text { whole-body approval for } \\
\text { all pacemaker systems }\end{array}$ & $\begin{array}{l}\text { Pacemaker system-dependent } \\
\text { whole-body approval or partial- } \\
\text { body approval (model-depen- } \\
\text { dent, upper isocenter limit above } \\
\text { thoracic vertebra } 1 \text { or } 10 \mathrm{~cm} \\
\text { above thoracic vertebra } 1 \text {, lower } \\
\text { isocenter limit below lumbar } \\
\text { vertebra 4) }\end{array}$ & $\begin{array}{l}\text { partial-body approval for all } \\
\text { pacemaker systems (isocenter } \\
\text { of FOV above the orbit or below } \\
\text { the major trochanter) }\end{array}$ \\
\hline maximum MRI examination time & no limitations & $\begin{array}{l}<30 \text { min per MRI examination } \\
<10 \text { hour maximum cumulative } \\
\text { MRI examination time per life } \\
\text { time of pacemaker system }\end{array}$ & no limitations & $\begin{array}{l}\text { Some pacemaker systems no } \\
\text { limitation, some systems } \\
<30 \text { min per MRI examination }\end{array}$ & $<40$ min per MRI examination \\
\hline maximum body size & no limitations & $1.40 \mathrm{~m}$ & no limitations & no limitations & $1.47 \mathrm{~m}$ \\
\hline body temperature & no limitations & $<38.0^{\circ} \mathrm{C}$ & $<38.0^{\circ} \mathrm{C}$ & $\begin{array}{l}\text { pacemaker systems with whole- } \\
\text { body approval: no limitation par- } \\
\text { tial-body approval: }<38.0^{\circ} \mathrm{C}\end{array}$ & $<38.0^{\circ} \mathrm{C}$ \\
\hline positional requirements & supine and prone position & only supine position & supine and prone position & supine and prone position & supine and prone position \\
\hline $\begin{array}{l}\text { additional cardiac leads or lead } \\
\text { components }{ }^{1}\end{array}$ & $\begin{array}{l}\text { no additional leads or lead } \\
\text { components }\end{array}$ & $\begin{array}{l}\text { additional coronary sinus leads } \\
\text { approved for some CRT systems, } \\
\text { otherwise no additional leads or } \\
\text { lead components }\end{array}$ & $\begin{array}{l}\text { no additional leads or lead } \\
\text { components }\end{array}$ & $\begin{array}{l}\text { no additional leads or lead } \\
\text { components }\end{array}$ & $\begin{array}{l}\text { no additional cardiac leads or } \\
\text { lead components }\end{array}$ \\
\hline $\begin{array}{l}\text { other cardiac and extracardiac } \\
\text { implants }\end{array}$ & $\begin{array}{l}\text { other implants approved as } \\
\text { "MR conditional" are permitted } \\
\text { within their conditions for use }\end{array}$ & $\begin{array}{l}\text { 1. other implants approved } \\
\text { as "MR conditional" are } \\
\text { permitted within their } \\
\text { conditions for use } \\
\text { 2. implants directly adjacent } \\
\text { to leads }(<4 \mathrm{~cm}) \text { may not be } \\
\text { longer than } 5 \mathrm{~cm}\end{array}$ & $\begin{array}{l}\text { warning notice in manuals: } \\
\text { "Other implants can impair the } \\
\text { safety of MR conditional pace- } \\
\text { maker systems" }\end{array}$ & no clear data in the manuals, & $\begin{array}{l}\text { According to manual “Implanted } \\
\text { non MR-safe medical products } \\
\text { are contraindicated” authors' } \\
\text { comment: therefore all metallic } \\
\text { implants which by definition } \\
\text { cannot be classified as MR-safe } \\
\text { are de facto contraindicated }\end{array}$ \\
\hline contact address & $\begin{array}{l}\text { Medtronic GmbH } \\
\text { Earl-Bakken-Platz } 140670 \\
\text { Meerbusch, Germany } \\
+492159-8149-0\end{array}$ & $\begin{array}{l}\text { BIOTRONIK SE \& Co. KG } \\
\text { Woermannkehre } 112359 \text { Berlin, } \\
\text { Germany } \\
+493068905-0\end{array}$ & $\begin{array}{l}\text { Boston Scientific } \\
\text { Daniel-Goldbach-Strasse } 17 \text { - } 27 \\
40880 \text { Ratingen, Germany } \\
+492102489750\end{array}$ & $\begin{array}{l}\text { St. Jude Medical GmbH } \\
\text { Helfmannpark 1, D65 } 760 \text { Es- } \\
\text { chborn, Germany } \\
+49619677110 \\
+4961967711177\end{array}$ & $\begin{array}{l}\text { Sorin Group Deutschland GmbH } \\
\text { Lindberghstr. } 25 \\
\text {, } 80939 \text { Munich, Germany } \\
\text { +4989323010 }\end{array}$ \\
\hline
\end{tabular}




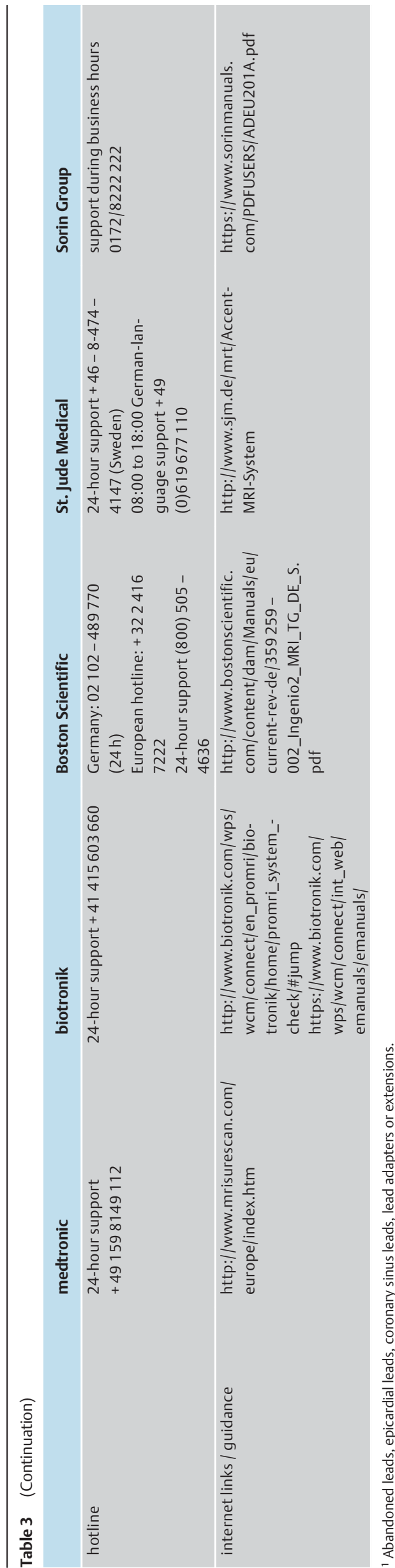

bel" use). In principle, however, patients must be informed of the same risks as those with conventional systems (see Algorithm 2). With respect to MR conditional systems, however, these risks have been widely minimized, so that the remaining theoretical risk according to the criteria of the approval authorities is considered reasonably low, taking into account the anticipated benefit of the MR examination. In individual cases, these risks cannot be ruled out with absolute certainty.

\section{Monitoring during the MR examination}

In principle, the presence of a cardiologist during the MRI scan of a patient with an MR conditional pacemaker system is not required as long as complications which may occur independent of the presence of a pacemaker can be detected and treated by attending medical staff until the arrival of an emergency team. The situation is comparable to the management of contrast agent-induced events during radiological examinations.

All manufacturers of MR conditional pacemakers require patient monitoring using the following methods during an MRI scan: pulse oximetry, ECG or blood pressure measurement. The user may select the monitoring modality. The authors of this position paper strongly recommend monitoring using an MRI-compatible pulse oximeter. The validity of ECG registrations (even with newer MRI-compatible ECG systems) is still frequently impaired by overlaying artifacts. Blood pressure measurement does not provide continuous monitoring of the patient. Pulse oximetry alone is considered sufficient for monitoring patients with MR conditional pacemaker systems.

\section{MRI-related conditions for use / safety precautions}

SAR value: To reduce RF-induced lead heating, the wholebody SAR value is limited for most MR conditional systems to the normal operating mode at an upper threshold of $2 \mathrm{~W} / \mathrm{kg}$ (local head SAR value $3.2 \mathrm{~W} / \mathrm{kg}$ ); see also the comment "SAR value" in the section "Conventional pacemakers". Some pacemaker systems made by Biotronik, Boston Scientific and St. Jude are also approved for MR examinations with a maximum SAR value of $4 \mathrm{~W} / \mathrm{kg}$ (local head SAR value $3.2 \mathrm{~W} / \mathrm{kg}$ ).

MRI coils: All currently commercially available receiver coils, including local surface receiver coils, can be used in all body regions for all pacemaker manufacturers. The integrated body-RF coil is approved for all pacemaker manufacturers as transmit coil. Some pacemaker manufacturers (Medtronic, Biotronik and Boston Scientific) also allow the use of combined transmit/receive coils outside the thoracic region which in relatively rare cases are available for some MRI systems as knee or head coils, for example.

Positioning: With the exception of the Biotronik company, MR conditional pacemaker systems of all manufacturers are approved for MR examinations in supine and prone position.

All Biotronik models are tested and approved only for MRI scans in supine position; consequently an MR examination of the breasts, which is performed in prone position, for example, cannot be accomplished as "in label" use on a patient with an MR conditional Biotronik pacemaker system as the specific MR-related conditions for use are not met.

- Table 3 contains a summary of additional manufacturer specifications for MR conditional pacemaker systems, such 
as MRI examination time, cumulative examination time over the service life time of the pacemaker pulse generator, minimum patient body size as well as exclusion of fever or impaired patient body temperature regulation.

Pacemaker-related conditions for use/safety precautions Analogously to the procedure with conventional pacemakers, prior to an examination, MR conditional systems should be programmed into an MRI-protection mode which implies: asynchronous mode or deactivation of the pacing function, bipolar lead configuration, increased stimulation output, deactivation of supplementary stimulation functions such as frequency-adapted stimulation or anti-tachycardia overstimulation. This MRI-protection mode is stored in the software options of the pacemaker model. This implies that before and after an MR examination, patients must always be seen by a cardiologist. Although the manufacturers do not pose explicit requirements, the authors of this paper suggest that reprogramming be performed as close in place and time to the MR examination as possible, ideally in the same or adjacent building, and within a time window of $<2 \mathrm{~h}$. This procedure, in the estimation of the attending cardiologist, can be modified in individual cases. This applies, for example, to patients for whom no pacemaker activity has been documented for an extended period.

Unlike conventional pacemaker systems, follow-up after 3 months to rule out long-term damage is optional and not obligatory.

\section{Summary: MRI and cardiac pacemakers \\ $\nabla$}

1. Conventional pacemaker systems are no longer an absolute but rather a relative contraindication for performing an MR examination. The procedural management includes the assessment of the individual risk/benefit ratio, comprehensive patient informed consent about specific related risks and "off label" use, extensive PM- and MRIrelated safety precautions as well as adequate monitoring techniques during the MRI exam

2. MR conditional pacemakers have been tested and approved under specific conditions ("in-label" use). Decisive for patient safety are precise understanding of, and compliance with, the terms of use for the specific pacemaker system. If the electrophysiological and MRI-specific conditions for use are not met or compliance with these conditions for use cannot be guaranteed, the device must be treated like a conventional pacemaker.

\section{Affiliations}

Department of Diagnostic and Interventional Radiology, German Red Cross Hospital Neuwied, Germany

2 Institute for Biomedical Engineering, Swiss Federal Institute of Technology (ETH Zurich) / University of Zurich, Switzerland

Department of Radiology and Nuclear Medicine, University Hospital Luebeck, Germany

${ }^{4}$ Department of Diagnostic and Interventional Radiology, University of Leipzig - German Heart Center Leipzig, Germany

Erwin L. Hahn Institute for MR Imaging, High Field and Hybrid MR Imaging, University Hospital Essen, Germany

${ }^{6}$ Department of Radiology and Nuclear Medicine, University Hospital Magdeburg, Germany

\section{Literatur}

1 Hundley WG, Bluemke DA, Finn JP et al. ACCF/ACR/AHA/NASCI/SCMR 2010 expert consensus document on cardiovascular magnetic resonance: a report of the American College of Cardiology Foundation Task Force on Expert Consensus Documents. Circulation 2010; 121: 2462- 2508

2 Schellinger PD, Bryan RN, Caplan LR et al. Evidence-based guideline: The role of diffusion and perfusion MRI for the diagnosis of acute ischemic stroke: report of the Therapeutics and Technology Assessment Subcommittee of the American Academy of Neurology. Neurology 2010; 75: $177-185$

3 [Anonym]. In Chest Pain of Recent Onset: Assessment and Diagnosis of Recent Onset Chest Pain or Discomfort of Suspected Cardiac Origin. London: 2010

4 Achenbach S, Barkhausen J, Beer M et al. Consensus Recommendations of the German Radiology Society (DRG), the German Cardiac Society (DGK) and the German Society for Pediatric Cardiology (DGPK) on the Use of Cardiac Imaging with Computed Tomography and Magnetic Resonance Imaging. Fortschr Röntgenstr 2012; 184: 345 - 368

5 Markewitz A. Annual Report 2011 of the German pacemaker and defibrillator register: Section pacemakers and AQUA-Institute for Applied Quality Improvement and Research in Health Care. Herzschrittmachertherapie \& Elektrophysiologie 2013; 24: 249-274

6 Kalin R, Stanton MS. Current clinical issues for MRI scanning of pacemaker and defibrillator patients. Pacing Clin Electrophysiol 2005; 28: $326-328$

7 Roguin A, Schwitter J, Vahlhaus C et al. Magnetic resonance imaging in individuals with cardiovascular implantable electronic devices. Europace 2008; 10 : $336-346$

8 Sommer T, Naehle CP, Yang A et al. Strategy for safe performance of extrathoracic magnetic resonance imaging at 1.5 tesla in the presence of cardiac pacemakers in non-pacemaker-dependent patients: a prospective study with 115 examinations. Circulation 2006; 114: 1285 1292

9 Levine GN, Gomes AS, Arai AE et al. Safety of magnetic resonance imaging in patients with cardiovascular devices: an American Heart Association scientific statement from the Committee on Diagnostic and Interventional Cardiac Catheterization, Council on Clinical Cardiology, and the Council on Cardiovascular Radiology and Intervention: endorsed by the American College of Cardiology Foundation, the North American Society for Cardiac Imaging, and the Society for Cardiovascular Magnetic Resonance. Circulation 2007; 116: 2878-2891

10 Nazarian $S$, Hansford $R$, Roguin A et al. A prospective evaluation of a protocol for magnetic resonance imaging of patients with implanted cardiac devices. Annals of internal medicine 2011; 155: 415-424

11 Nazarian S, Halperin HR. How to perform magnetic resonance imaging on patients with implantable cardiac arrhythmia devices. Heart Rhythm 2009; 6: 138-143

12 Roguin A, Zviman MM, Meininger GR et al. Modern pacemaker and implantable cardioverter/defibrillator systems can be magnetic resonance imaging safe: in vitro and in vivo assessment of safety and function at $1.5 \mathrm{~T}$. Circulation 2004; 110: $475-482$

13 Nazarian S, Beinart $R$, Halperin HR. Magnetic resonance imaging and implantable devices. Circ Arrhythm Electrophysiol 2013; 6: 419-428

14 Sommer T, Vahlhaus C, Lauck G et al. MR imaging and cardiac pacemakers: in-vitro evaluation and in-vivo studies in 51 patients at $0.5 \mathrm{~T}$. Radiology 2000; 215: $869-879$

15 Luechinger R, Duru F, Scheidegger MB et al. Force and torque effects of a 1.5-Tesla MRI scanner on cardiac pacemakers and ICDs. Pacing and clinical electrophysiology: PACE 2001; 24: 199-205

16 Luechinger $R$, Duru F, Zeijlemaker VA et al. Pacemaker reed switch behavior in $0.5,1.5$, and 3.0 Tesla magnetic resonance imaging units: are reed switches always closed in strong magnetic fields? Pacing and clinical electrophysiology: PACE 2002; 25: 1419-1423

17 Luechinger R, Zeijlemaker VA, Pedersen EM et al. In vivo heating of pacemaker leads during magnetic resonance imaging. European heart journal 2005; 26: 376-383; discussion 325-377

18 Tandri H, Zviman MM, Wedan SR et al. Determinants of gradient fieldinduced current in a pacemaker lead system in a magnetic resonance imaging environment. Heart rhythm: the official journal of the Heart Rhythm Society 2008; 5: $462-468$

19 Nordbeck P, Weiss I, Ehses P et al. Measuring RF-induced currents inside implants: Impact of device configuration on MRI safety of cardiac pacemaker leads. Magnetic resonance in medicine: official journal of the 
Society of Magnetic Resonance in Medicine / Society of Magnetic Resonance in Medicine 2009; 61: 570-578

20 Naehle CP, Meyer C, Thomas D et al. Safety of brain 3-T MR imaging with transmit-receive head coil in patients with cardiac pacemakers: pilot prospective study with 51 examinations. Radiology 2008; 249: 991 1001

21 Naehle CP, Strach K, Thomas D et al. Magnetic resonance imaging at 1.5$\mathrm{T}$ in patients with implantable cardioverter-defibrillators. J Am Coll Cardiol 2009; 54: 549-555

22 Naehle $C P$, Zeijlemaker $V$, Thomas $D$ et al. Evaluation of cumulative effects of MR imaging on pacemaker systems at 1.5 Tesla. Pacing Clin Electrophysiol 2009; 32: 1526-1535

23 Schmiedel A, Hackenbroch M, Yang A et al. Magnetic resonance imaging of the brain in patients with cardiac pacemakers. Experimental and clinical investigations at 1.5 Tesla. Rofo 2005; 177: 731 - 744

24 Strach $K$, Naehle CP, Muhlsteffen A et al. Low-field magnetic resonance imaging: increased safety for pacemaker patients? Europace 2010; 12: $952-960$

25 Nazarian S, Roguin A, Zviman MM et al. Clinical utility and safety of a protocol for noncardiac and cardiac magnetic resonance imaging of patients with permanent pacemakers and implantable-cardioverter defibrillators at 1.5 tesla. Circulation 2006; 114: $1277-1284$

26 Martin ET, Coman JA, Shellock FG et al. Magnetic resonance imaging and cardiac pacemaker safety at 1.5-Tesla. J Am Coll Cardiol 2004; 43: $1315-1324$
27 Mollerus M, Albin G, Lipinski $M$ et al. Cardiac biomarkers in patients with permanent pacemakers and implantable cardioverter-defibrillators undergoing an MRI scan. Pacing Clin Electrophysiol 2008; 31 : $1241-1245$

28 Mollerus M, Albin G, Lipinski $M$ et al. Magnetic resonance imaging of pacemakers and implantable cardioverter-defibrillators without specific absorption rate restrictions. Europace 2010; 12: 947-951

29 Brignole M, Auricchio A, Baron-Esquivias G et al. 2013 ESC Guidelines on cardiac pacing and cardiac resynchronization therapy: the Task Force on cardiac pacing and resynchronization therapy of the European Society of Cardiology (ESC). Developed in collaboration with the European Heart Rhythm Association (EHRA). Eur Heart J 2013; 34: $2281-2329$

30 Medizinische elektrische Geräte Teil 2-33: Besondere Festlegungen für die Sicherheit von Magnetresonanzgeräten für die medizinische Diagnostik, DIN EN 60601-2-33

31 Sutton R, Kanal E, Wilkoff BL et al. Safety of magnetic resonance imaging of patients with a new Medtronic EnRhythm MRI SureScan pacing system: clinical study design. Trials 2008; 9: 68

32 Gimbel JR, Bello D, Schmitt M et al. Randomized trial of pacemaker and lead system for safe scanning at 1.5 Tesla. Heart rhythm: the official journal of the Heart Rhythm Society 2013; 10: 685-691

33 Wilkoff BL, Bello D, Taborsky $M$ et al. Magnetic resonance imaging in patients with a pacemaker system designed for the magnetic resonance environment. Heart rhythm: the official journal of the Heart Rhythm Society 2011; 8: 65-73 